\title{
The Effects of Valproic Acid on the Skeletal Development and the Ameliorative Effects of Combined Use of Folic Acid and Vitamin E in Pregnant Albino Rats
}

\author{
Gamal Abdel Salam*, Omar ABd Alaziz Allam \\ Anatomy Department, Faculty of Medicine, Benha University, Benha City, Egypt \\ Email address: \\ drgamal19@yahoo.com (G. A. Salam)
}

\section{To cite this article:}

Gamal Abdel Salam, Omar ABd Alaziz Allam. The Effects of Valproic Acid on the Skeletal Development and the Ameliorative Effects of Combined Use of Folic Acid and Vitamin E in Pregnant Albino Rats. International Journal of Clinical and Developmental Anatomy.

Vol. 1, No. 3, 2015, pp. 70-78. doi: 10.11648/j.ijcda.20150103.13

\begin{abstract}
Objectives: To evaluate skeletal developmental defects secondary to chronic valproic acid (VPA) use during pregnancy and the extent of ameliorative effect of combined use of vitamin E and folic acid (FA) during VPA therapy. Materials and Methods: Thirty virgin female albino rats were allowed to get pregnant and were divided into three equal groups: Control group received no medications; VPA group received oral VPA $400 \mathrm{mg} / \mathrm{kg}$ body weight (BW) starting on gestational day (GD) 1 till GD20 and Prophylaxis group received oral VPA (400 mg/kg BW) and vitamin E $250 \mathrm{mg} / \mathrm{kg} \mathrm{BW}$ and folic acid $100 \mu \mathrm{g} / \mathrm{kg}$ BW using gastric tube starting on GD1 till GD20. At GD20, uterine horns were examined for resorption sites, alive or dead fetuses. Extracted living fetuses were examined for BW, crown-rump length (CRL), and antero-posterior (AP) and biparietal diameters and for congenital malformations. Results: VPA significantly reduced all body measurements of living dams compared to control dams. Prophylaxis therapy significantly increased BW, CRL and AP skull diameter compared to VPA dams. The GD20 fetus of VPA group showed delayed ossification of skull bones with wide anterior fontanel (AF) and widely separated parietal bones, very small ossification center (OC) for hyoid bone. Caudal vertebrae were unossified or showed very small OC with no evident OC for calcaneous, metatarsal bones or distal phalanges. Fetuses of prophylaxis group showed slightly wide AF than that of control animals and parietal bones are separated to lesser extent than VPA group. Mandible is developed, with an OC for hyoid bone and sternebrae are seen. Six caudal vertebrae and few OC in phalanges are seen, but no OC in calcaneous. Conclusion: VPA chronic administration during pregnancy showed deleterious effects on fetal body measurements and skeletal system development. Concomitant administration of vitamin E and FA significantly ameliorated these changes.
\end{abstract}

Keywords: Valproic Acid, Folic Acid, Vitamin E, Pregnancy, Skeletal Defects

\section{Introduction}

Epilepsy is the third most common chronic neurological disorder. Epilepsy has wide-ranging physiologic consequences that arise from seizures and from the use of antiepileptic drugs. The Centers for Disease Control and Prevention estimated that epilepsy currently affects 2.2 million Americans and 65 million people worldwide, while the National Institutes of Health estimates that bipolar disorder affects approximately $2.6 \%$ of the U.S. population, with the average onset of the disorder occurring at age 25 , the middle of child-bearing years for women ${ }^{(1,2)}$

Valproic acid (VPA) is a widely-used first-generation antiepileptic drug, prescribed predominantly in epilepsy and psychiatric disorders to control epileptic seizures and regulate the mania associated with bipolar disorder. VPA has good efficacy and pharmacoeconomic profiles ${ }^{(3)}$.

Adverse drug reactions are a major public health concern and a leading cause of morbidity and mortality in the world. In the case of antiepileptic drugs (AED), adverse drug reactions constitute a barrier to successful treatment since they decrease treatment adherence and impact patients' quality of life of patients. In late 2009, the Food and Drug Administration released a warning indicating that there is an increased risk for major birth defects, including craniofacial, neural, cardiac and cognitive defects, associated with VPA therapies applied during pregnancy ${ }^{(4)}$.

Valporic acid has its inherent toxicity including 
hepatotoxicity and increased risk of fetal malformations if received during pregnancy. There have been 268 Individual case safety reports with VPA and fatal outcome, reported a total of 156 fatalities with hepatotoxicity, 31 fatalities with pancreatitis. Hepatotoxicity was disproportionally and most commonly reported in children aged $\leq 6$ years ( $104 / 156$ reports) but affected children of all ages and polytherapy was significantly more frequently reported for VPA with fatal outcome (58\%) compared with non-fatal outcome $(34 \%)^{(5)}$.

Existing literature shows that pharmacokinetic and pharmacodynamics drug-drug interactions possibly occur with the use of a combination of VPA and the atypical antipsychotics olanzapine and quetiapine ${ }^{(6)}$. Between $30 \%$ and $50 \%$ of patients with brain tumors first present with a seizure, and up to $30 \%$ more will develop seizures later. Therefore, optimal management of these patients requires the use of antiseizure medications; however, VPA, despite its efficacy for seizure control, it may also increase the hematologic toxicity of antineoplastic drugs, presumably by inhibiting their metabolism, and may independently impair hemostasis, which is of some concern for patients who require surgical intervention ${ }^{(7)}$.

During fetal development, in the $4^{\text {th }}$ week, two cartilaginous centers appear on either side of the notochord and extend around it to form the body of the cartilaginous vertebra. A second pair of cartilaginous foci appears in the lateral parts of the vertebral bow, grow backward on either side of the neural tube to form the cartilaginous vertebral arch, and a separate cartilaginous center appears for each costal process. By the $8^{\text {th }}$ week, the cartilaginous arch has fused with the body, and in the $4^{\text {th }}$ month, the two halves of the arch are joined on the dorsal aspect of the neural tube. The spinous process is developed from the junction of the two halves of the vertebral arch. The transverse process grows out from the vertebral arch behind the costal process ${ }^{(8,9,10)}$.

The ribs are formed from the ventral or costal processes of the primitive vertebral bows. The ventral ends of the ribs become united by a longitudinal bar termed the sternal plate, and opposite the first seven pairs of ribs these sternal plates fuse in the middle line to form the manubrium and body of the sternum. The xiphoid process is formed by a backward extension of the sternal plates ${ }^{(11)}$.

The notochord extends as far forward as the anterior end of the mid-brain, and becomes partly surrounded by mesoderm and its posterior part corresponds with the basilar part of the occipital bone. Then, the mesoderm extends over the brain-vesicles, and thus the entire brain is enclosed by a mesodermal investment, which is termed the membranous cranium and from its inner layer, the bones of the skull and the membranes of the brain are developed, while from its outer layer the muscles, blood vessels, true skin, and subcutaneous tissues of the scalp are developed ${ }^{(12,13)}$.

The current experimental animal study was designed to evaluate the skeletal developmental defects secondary to chronic use of VPA during pregnancy and the extent of the ameliorative effect of combined use of vitamin $\mathrm{E}$ and folic acid during VPA therapy.

\section{Materials and Methods}

\subsection{Animals}

The study comprised 30 virgin healthy female albino rats, weighing 200-250 gm. Albino rats were chosen for low incidence of spontaneously occurring congenital defects, short-gestational span and high offspring number. Rats were purchased from the laboratories of Ministry of Agriculture, and kept under standard conditions, temperature $20^{\circ} \mathrm{C}$, humidity $60 \%$ and 12-hs day/night cycle, and maintained on standard diet and free water supply till the start of study regimens.

The study also included 10 male rats used to commit intercourse with female rats to get pregnant. Intercourse was assured by getting vaginal smear and detecting sperms and this was considered as gestation day-1 (GD1).

\subsection{Study Protocol}

The pregnant animals were divided into three groups (each in a separate cage) according to medication regimen used:

i. Control group included 10 rats kept on normal diet without any medications.

ii. VPA group included 10 rats received valproic acid (Depakene) $400 \mathrm{mg} / \mathrm{kg} \mathrm{BW}$ orally using gastric tube starting on GD1 till GD20.

iii. Prophylaxis group included 10 rats received oral valproic acid (Depakene) $400 \mathrm{mg} / \mathrm{kg} \mathrm{BW}$ in addition to vitamin E $250 \mathrm{mg} / \mathrm{kg} \mathrm{BW}$ and folic acid $100 \mu \mathrm{g} / \mathrm{kg} \mathrm{BW}$ orally using gastric tube starting on GD1 till GD20.

\subsection{Sample Obtaining and Measurements}

At the $20^{\text {th }}$ day of gestation, female rats were ether anesthetized and a midline longitudinal incision was made in the anterior abdominal wall to expose the abdominal cavity. Uterine horns were examined for resorption sites that appeared as small-to-large blood clots which indicate post-implantation death. Uterine horns were incised and alive or dead fetuses were extracted and their number was counted. Extracted living fetuses were examined for body measurements including body weight $(\mathrm{BW})$, crown-rump length (CRL), and antero-posterior (AP) and biparietal diameters using micrometer.

\subsection{Technique of Skeletal Staining}

Fetuses were put in ethyl alcohol 95\% and totally eviscerated of internal organs through midline abdominal incision and were skinned by immersion in water path heated up to $70 \mathrm{oC}$ for $30 \mathrm{sec}$ and then were placed again in ethyl alcohol $95 \%$ for 7 days. Then, animal remnant was cleared in $\mathrm{KOH} 1 \%$ for 1-3 days until bones become clearly visible through surrounding tissues. Animals were stained by immersion for one day in freshly prepared $\mathrm{KOH} 0.5 \%$ to which 10 drops of conc. Alizarin red stain were added, then specimens were decolorized using a solution of mixture of glycerin, $\mathrm{KOH} 0.5 \%$ in distilled water of 20:1:79 volume: volume. Specimens were immersed in glycerin solution of 
ascending concentration 30, 50 and $70 \%$ and were preserved in pure glycerin to which a crystal of thymol was added to prevent fungal contamination.

\subsection{Evaluation of Ossification}

Skeletal ossification was assessed according Burdan et al. (14) as following:

i. Un-ossified: means no ossification as judged by absence of alizarin red stain.

ii. Incomplete ossification: means partial ossification as judged by reduced alizarin red stain.

iii. Miss-happen means abnormally shaped ossification.

\subsection{Statistical Analysis}

Obtained data were presented as mean $\pm \mathrm{SD}$, ranges, numbers and ratios. Results were analyzed using Wilcoxon; ranked test for unrelated data (Z-test) and Chi-square test $\left(\mathrm{X}^{2}\right.$ test). Statistical analysis was conducted using the SPSS (Version 15, 2006, SPSS, Inc., Chicago, IL, USA) for Windows statistical package. $\mathrm{P}$ value $<0.05$ was considered statistically significant.

\section{Results}

Examination of the gravid uteri defined 138 living dams, 11 dead dams and 6 resorption sites. No dead dams or resorption sites were detected in control group, while the frequency of dead dams and resorption sites was significantly $(\mathrm{p}<0.05)$ higher in VPA group compared both to control and prophylaxis groups with non-significantly $(\mathrm{p}>0.05)$ higher frequency in prophylaxis group compared to control group (Table 1).

Table 1. Pregnancy outcome of animals of studied groups.

\begin{tabular}{lllll}
\hline & $\begin{array}{l}\text { Control } \\
\text { group }\end{array}$ & $\begin{array}{l}\text { VPA } \\
\text { group }\end{array}$ & $\begin{array}{l}\text { Prophylaxis } \\
\text { group }\end{array}$ & Total \\
\hline Living dams & $52(100 \%)$ & $36(72 \%)$ & $50(94.3 \%)$ & $\begin{array}{l}138 \\
(89 \%)\end{array}$ \\
$\begin{array}{l}\text { Dead dams } \\
\text { Resorption } \\
\text { sites }\end{array}$ & 0 & $9(18 \%)$ & $2(3.8 \%)$ & $11(7.1 \%)$ \\
$\begin{array}{l}\text { Total } \\
\begin{array}{l}\text { Statistical } \\
\text { significance }\end{array}\end{array}$ & $52(100 \%)$ & $50(100 \%)$ & $53(100 \%)$ & $\begin{array}{l}155 \\
(100 \%)\end{array}$ \\
\hline
\end{tabular}

Data are presented as numbers; percentages are in parenthesis; P1: significance of difference between control and VPA groups; P2: significance of difference between control and prophylaxis groups; P3: significance of difference between prophylaxis and VPA groups

Exposure to VPA significantly $(\mathrm{p}<0.05)$ reduced all body measurements of living dams including body weight (BW), crown-rump length (CRL) and skull dimensions compared to control dams. Prophylaxis therapy ameliorated these development retardation effects of VPA manifested as significant $(p<0.05)$ increase of BW, CRL and AP skull diameter with non-significant $(\mathrm{p}>0.05)$ increase of biparaital skull diameter compared to VPA dams. Moreover, dams of prophylaxis group showed non-significant $(\mathrm{p}>0.05)$ reduction of CRL and biparietal skull diameter compared to control dams, despite of the significant $(\mathrm{p}<0.05)$ reduction of $\mathrm{BW}$, and skull AP diameter (Table 2, Fig. 1-4).

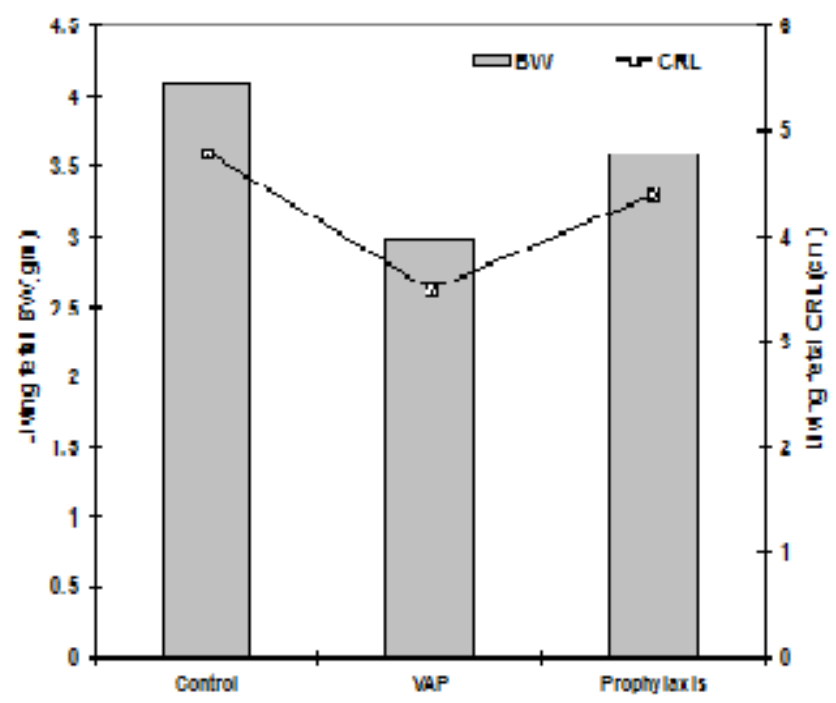

Fig. (1). Mean body weight and crowen-rump length of living dams of studied groups compared to control group

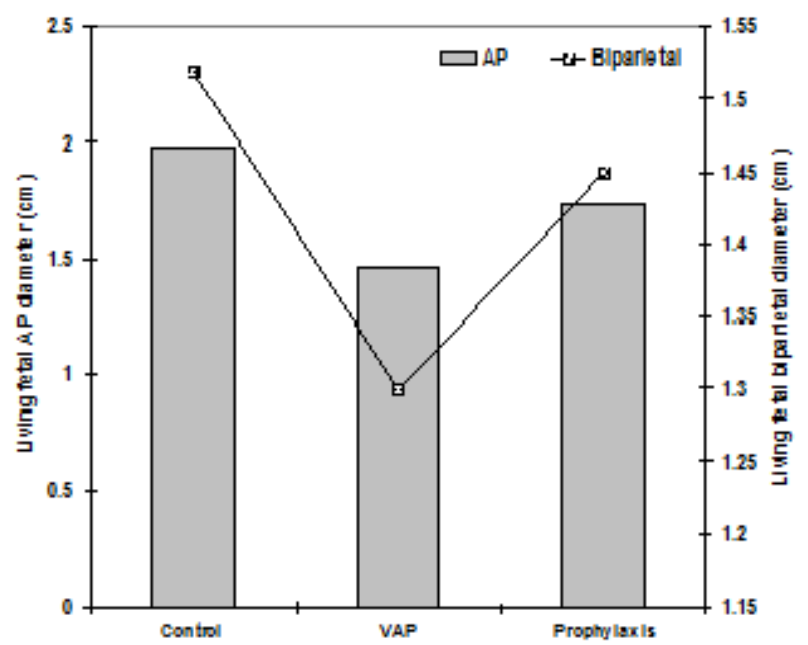

Fig. (2). Mean skull diameters of living dams of studied groups compared to control group 


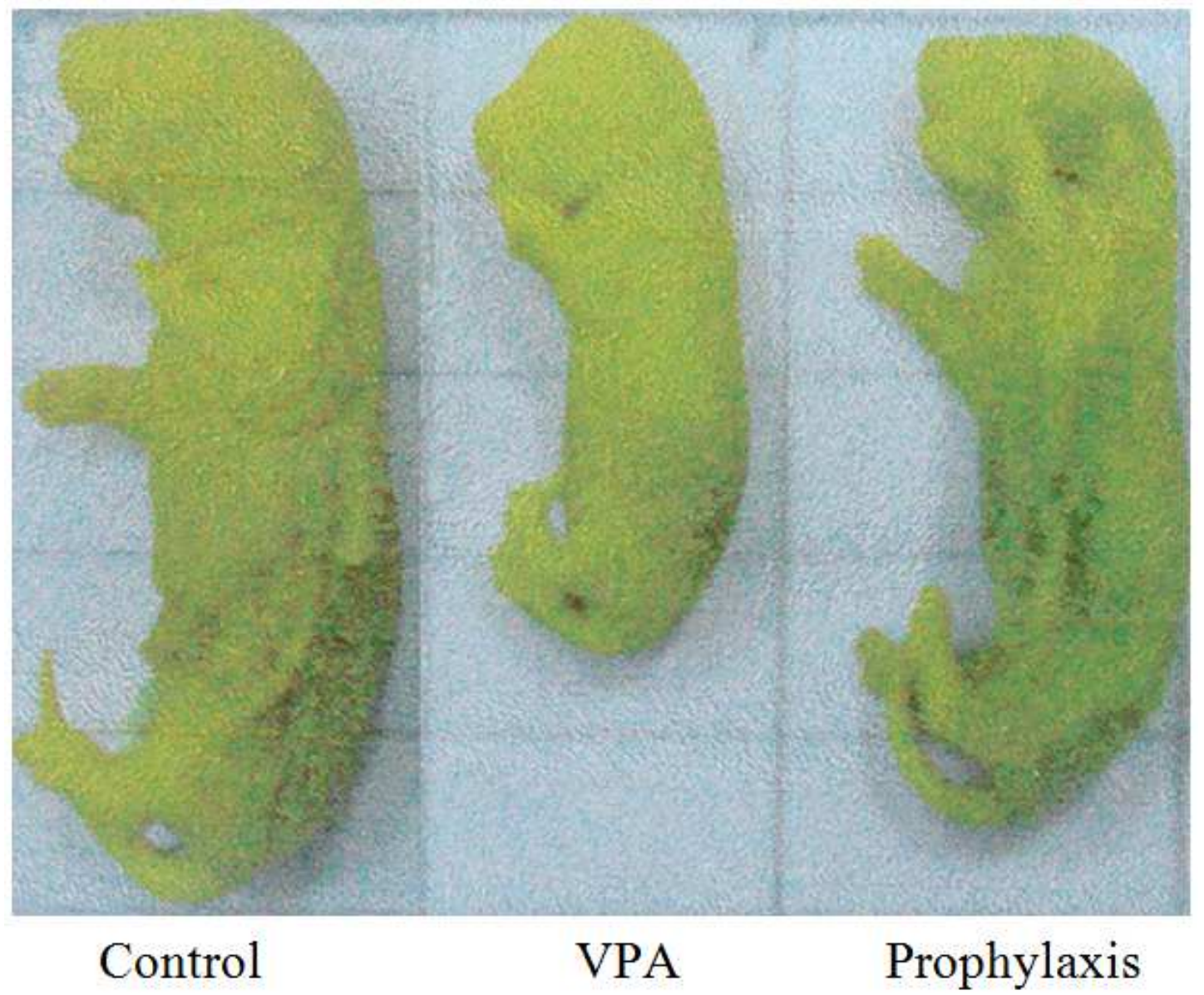

Fig. 3. Shows samples of fetuses of studied groups illustrating the difference of CRL.

Table 2. Body measurements of living dams of studied groups.

\begin{tabular}{lllll}
\hline & $\begin{array}{l}\text { Control } \\
\text { group }\end{array}$ & $\begin{array}{l}\text { VPA } \\
\text { group }\end{array}$ & $\begin{array}{l}\text { Prophylaxis } \\
\text { group }\end{array}$ & $\begin{array}{l}\text { Statistical } \\
\text { significance }\end{array}$ \\
\hline $\begin{array}{l}\text { Birth weight } \\
\text { (gm) }\end{array}$ & $4.1 \pm 0.47$ & $2.98 \pm 0.62$ & $3.59 \pm 0.39$ & $\begin{array}{l}\mathrm{P} 1=0.008 \\
\mathrm{P} 2=0.036 \\
\mathrm{P} 3=0.010\end{array}$ \\
& & & & $\begin{array}{l}\mathrm{P} 1=0.003 \\
\mathrm{P} 2=0.139\end{array}$ \\
$\begin{array}{l}\text { Crown-rump } \\
\text { length }(\mathrm{cm})\end{array}$ & $4.8 \pm 0.5$ & $3.5 \pm 0.53$ & $4.4 \pm 0.51$ & $\begin{array}{l}\mathrm{P} 3=0.005 \\
\text { P1 } 1=0.009\end{array}$ \\
$\begin{array}{l}\text { AP diameter } \\
(\mathrm{cm})\end{array}$ & $1.98 \pm 0.32$ & $1.46 \pm 0.25$ & $1.73 \pm 0.2$ & $\begin{array}{l}\mathrm{P} 2=0.011 \\
\mathrm{P} 3=0.012\end{array}$ \\
& & & & $\begin{array}{l}\mathrm{P} 1=0.015 \\
\text { Biparietal }\end{array}$ \\
diameter $(\mathrm{cm})$ & $1.52 \pm 0.16$ & $1.3 \pm 0.22$ & $1.45 \pm 0.17$ & $\begin{array}{l}\mathrm{P} 20.05 \\
\mathrm{P} 3>0.05\end{array}$ \\
\hline
\end{tabular}

Data are presented as mean $\pm \mathrm{SD} ; \mathrm{P} 1$ : significance of difference between control and VPA groups; P2: significance of difference between control and prophylaxis groups; P3: significance of difference between prophylaxis and VPA groups

\subsection{Assessment of Bone Staining}

\subsubsection{Control Group}

The 20-day fetus of control rat showed normal ossification of skull bones with small anterior fontanel (Fig. 4a), well-developed ossified mandible, hyoid bone, 6 sternebrae and vertebrae (Fig. 4b). Appendicular skeleton of the fore and hind limbs appeared ossified with apparent small ossification centers for calcaneous, metatarsal bones and distal phalanges (Fig. 4c)

\subsubsection{VPA Group}

The 20-day fetus of experimental rat of VPA group showed delayed skeletal development shown as delayed ossification of skull bones with wide anterior fontanel and widely separated parietal bones (Fig. 5a), very small ossification center for the hyoid bone (Fig. 5b). Caudal vertebrae were either unossified or showed very small ossification centers. Moreover, no evident ossification centers for calcaneous or metatarsal bones and distal phalanges were found (Fig. 5c)

\subsubsection{Prophylaxis Group}

The 20-day fetus of experimental rat of prophylaxis group showed improved skeletal development shown as slightly wide anterior fontanel than that of control animals and both parietal bones are separated but to lesser extent than animals of VPA group (Fig. 6a). Mandible is developed, with an ossification center for hyoid bone and 5 sternebrae are seen (Fig. 6b), while the $5^{\text {th }}$ sternebra in addition to a small ossification center in calcaneous is seen (Fig. 6c). Six caudal vertebrae and few centers in phalanges are seen, but no ossification center in calcaneous (Fig. 6d). 
Control group

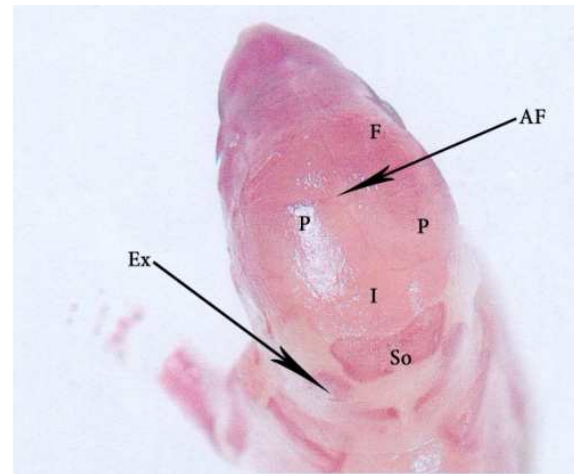

Fig. 4a. A photograph of 20-day fetus of control group showing ossified skull bones; parietal (P), inter-parietal (I), supraoccipital (So) and exoccipital (Ex) bones and anterior fontanelle. Alizarin red $x 8$.

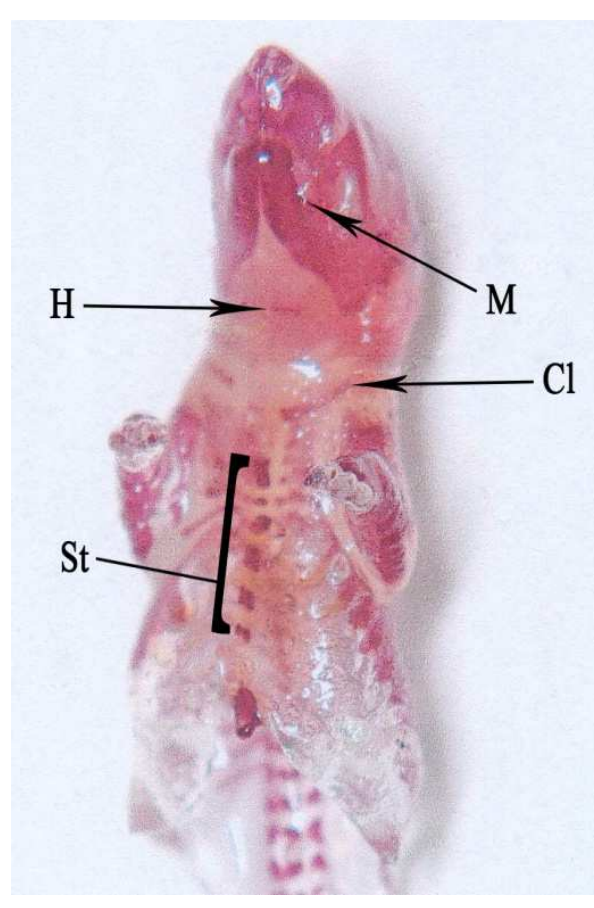

Fig. 4b. A photograph of 20-day fetus of control group showing well-developed ossified mandible $(M)$, hyoid bone $(\mathrm{H})$, clavicle $(\mathrm{Cl})$ and 6 sternebrae. Alizarin red $x 4$.
VPA group

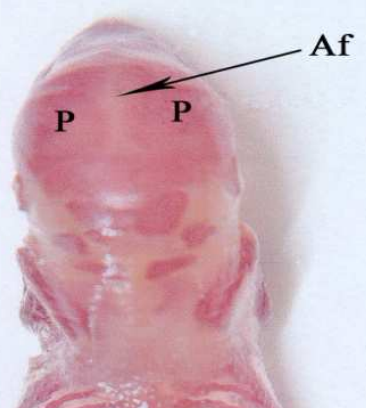

Fig. 5a. A photograph of 20-day fetus of rat of $A E D$ group showing large anterior fontanelle $(A F)$ with separation of the two parietal bones (P). Alizarin red $x 4$

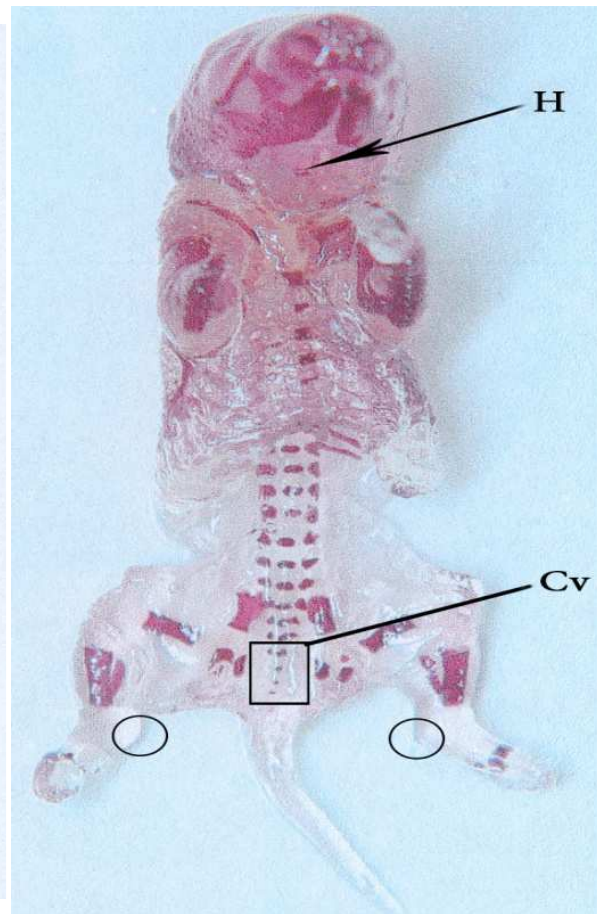

Fig. 5b. A photograph of 20-day fetus of rat of AED group showing very small ossification center for hyoid bone (H), 5 very small vertebrae with only 4 small ossification centers for caudal vertebrae ( $\mathrm{Cv}$ ). No ossification center for calcaneous was seen (empty ring). Alizarin red $x 4$.
Prophylaxis group

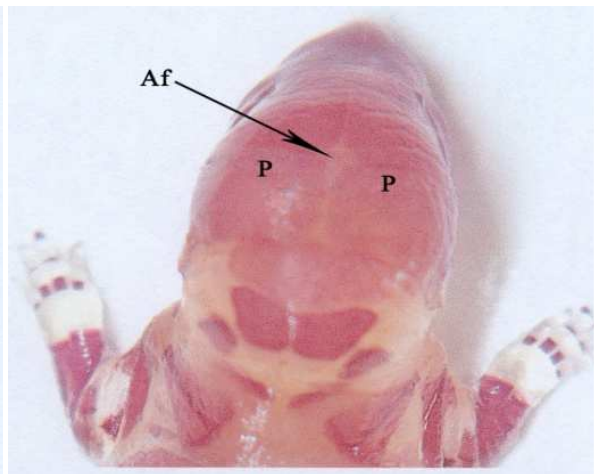

Fig. 6a. A photograph of 20-day fetus of rat of prophylaxis group showing anterior fontanelle which is slightly wider than that of control animals. Both parietal bones are separated but to lesser extent than animals of AED group. Alizarin red $x 4$.

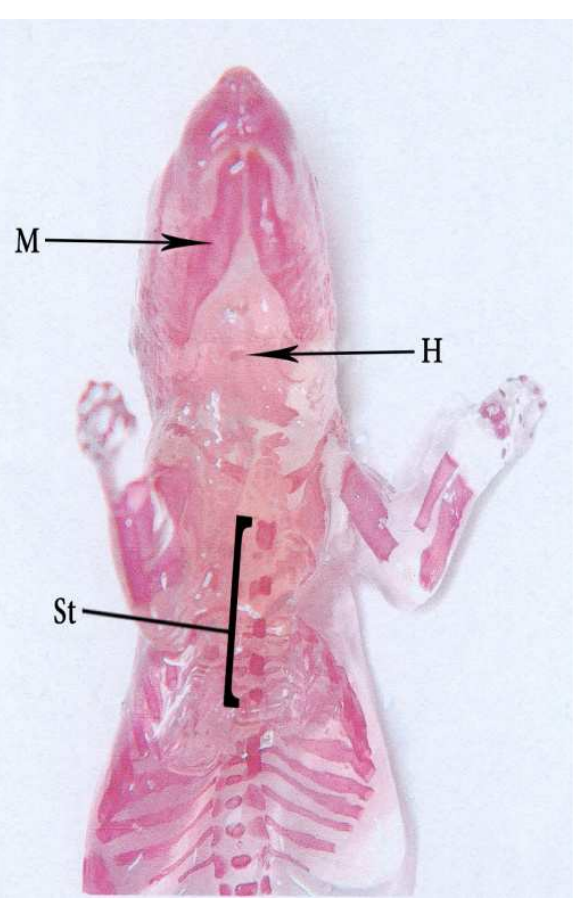

Fig. 6b. A photograph of 20-day fetus of rat of prophylaxis group showing developed mandible, an ossification center for hyoid bone $(H)$ and 5 sternebrae are seen. Alizarin red $x 8$. 

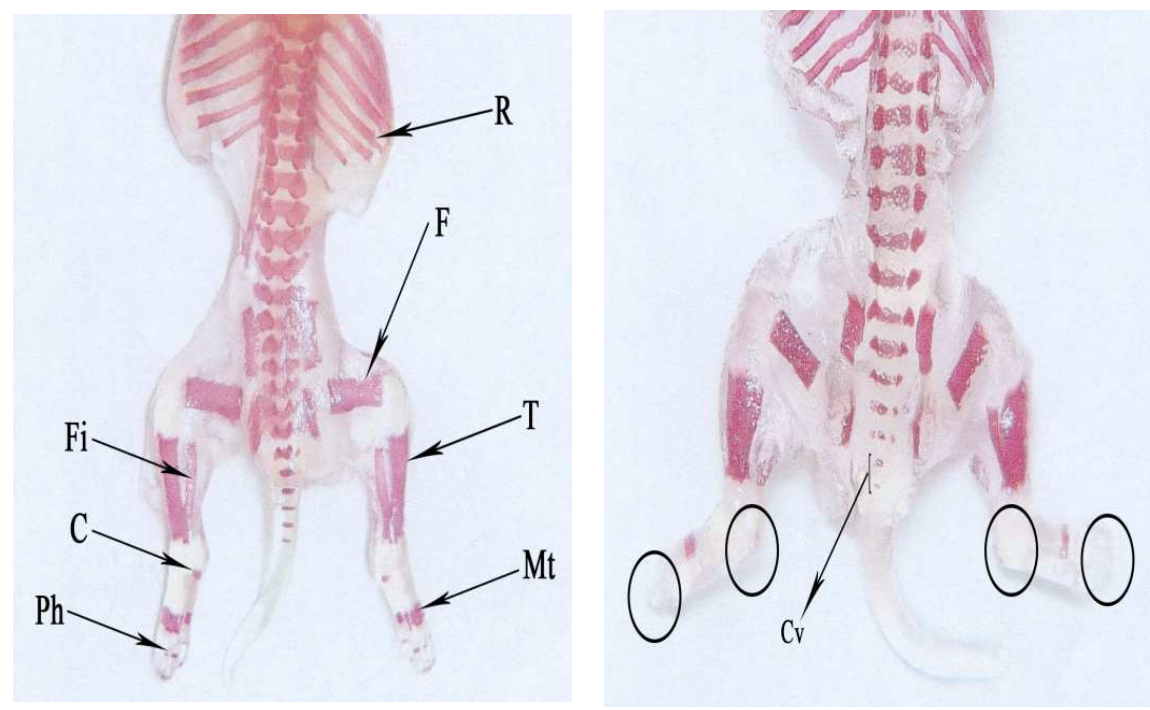

Fig. 4c. A photograph of 20-day fetus of control group showing ossified ribs (R), vertebrae (8 caudal vertebrae are seen). Ossified appnedicalur system was shown as ossified femur (F), tibia (T), fibula (Fi). Ossification centers for calcaneous (C), metatarsal bones (Mt) and phalanges $(P h)$ Alizarin red $x 4$. (empty rings). Alizarin red $x 4$.

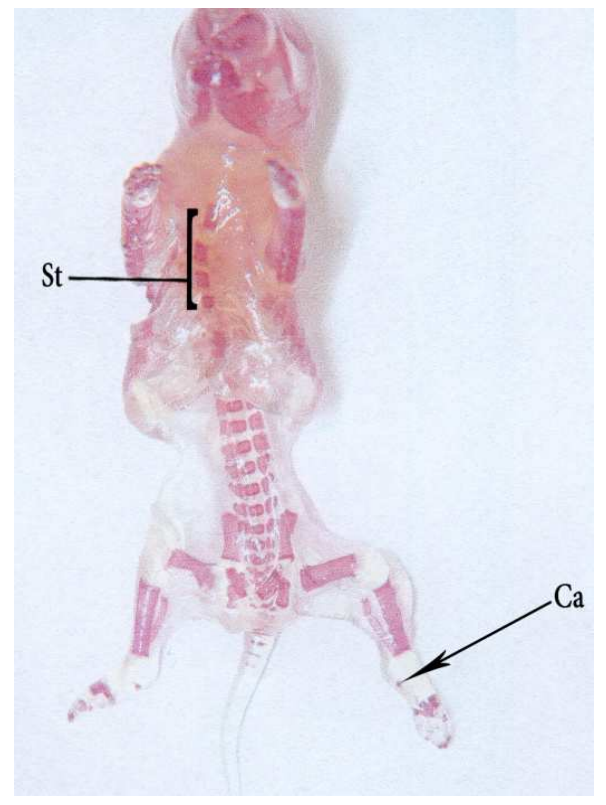

Fig. 5c. A photograph of 20-day fetus of rat of AED group showing two very small ossification centers for caudal vertebrae (Cv). No ossification centers for calcaneous or phalanges were seen
Fig. 6c. A photograph of 20-day fetus of rat of prophylaxis group showing absence of $5^{\text {th }}$ sternebra and only 5 are shown. A small ossification center in calcaneous is seen. Alizarin red $x 3$.

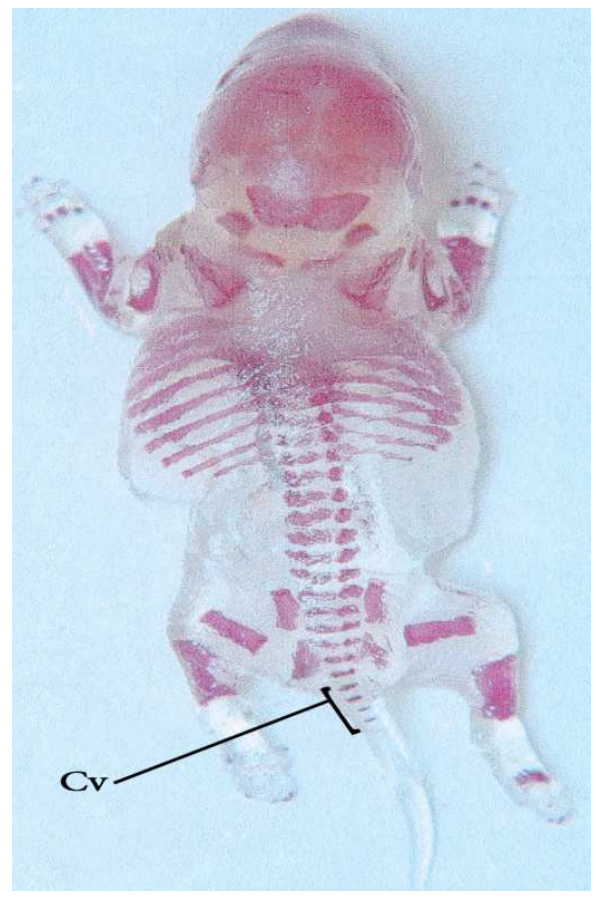

Fig. 6d. A photograph of 20-day fetus of rat of prophylaxis group showing 6 caudal vertebrae, few centers in phalanges, but no ossification center in calcaneous. Alizarin red $x 4$. 


\section{Discussion}

The obtained results illustrated the effect of valproic acid (VPA) if used during pregnancy manifested firstly as significant reduction of birth weight (BW) and crown-rump length (CRL) with diminution of skull dimensions of studied fetuses of VPA group compared to control group. However, combined prophylactic therapy using vitamin $\mathrm{E}$ and folic acid (FA) could ameliorate these effects of VPA allowing better development manifested as more weight gain and increased CRL and skull dimensions.

Secondly, VPA affected ossification and development of axial and appendicular bones manifested as reduced hyoid bone ossification center, hypoplastic mandible, reduced or absent centers for sternebrae, delayed caudal vertebral ossification and absence of ossification centers for calcaneous and metatarsals. Prophylactic therapy improved these changes with well-development of mandible, increased number of centers for sternebrae and appearance of ossification centers of calcaneous and metatarsals.

These findings go in hand with that previously reported in literature concerning the use of anti-epileptic drugs (AED) during pregnancy and with trials to evaluate prophylactic use of FA \&/or antioxidants. In a similar study; Baran et al. ${ }^{(15)}$ found administration of single VPA dose $(300 \mathrm{mg} / \mathrm{kg})$ resulted in weight and length loss between control and VPA groups, however, length and weight differences between groups received vitamin $\mathrm{E}$ or folate were not significant. Ornoy ${ }^{(16)}$ documented that exposure to VPA in pregnancy is associated with approximately three-fold increase in the rate of major anomalies, mainly spina bifida and only rarely anencephaly, cardiac, craniofacial, skeletal and limb defects and a possible set of dysmorphic features, the "valproate syndrome" with decreased intrauterine growth.

Soysal et al. ${ }^{(17)}$ using $25 \mathrm{mg} / \mathrm{kg} /$ day phenytoin administered intraperitoneally to pregnant rats detected that fetuses were $14 \%$ shorter and the weights $13 \%$ lower compared to control animals with decreased number of the fetuses obtained in one gestation by $9 \%$, and deteriorated ossification of skull bones, costal separation anomaly, the laterally-separated costal components were not attached to the costal arch with shape malformations in the last two ribs and wide angularity, particularly in the last six ribs.

Fadel et al. ${ }^{(18)}$ detected significant increases in skeletal abnormalities, particularly in ribs in topiramate-exposed fetuses at therapeutic doses compared to control group with a direct correlation between fetal $\mathrm{BW}$ and the number of complete ossified vertebral centers. Koo \& Zavras (19) indicated that various forms of VPA and newer generation AED agents show signals for congenital jaw or oral malformation.

Recently, in 2015; Tanoshima et al. ${ }^{(20)}$ documented that at present, risks of VPA-associated congenital malformations are 2 to 7 fold higher than other common antiepileptic drugs, and so VPA should not be used as a first-line therapy in women of childbearing age unless it is the only option for the patient.

In line with the use of antioxidant and FA therapy for reduction of the frequency and severity of AED-induced teratogenic effects; Al Deeb et al. ${ }^{(21)}$ found concomitant vitamin $\mathrm{E}$ administration significantly attenuated VPA induced decrease in fetal weight, crown rump length and malformations. Padmanabhan \& Shafiullah ${ }^{(22)}$ documented that plasma levels of FA and vitamin B12 must be kept substantially elevated and maintained high throughout organogenesis period to protect embryos against VPA-induced neural tube defects. Dawson et al. ${ }^{(23)}$ hypothesized that FA and pantothenic acid protect embryos from VPA-induced neural tube defects possibly through prevention of VPA-induced alterations in proteins involved in neurulation. Also, Hsieh et al. ${ }^{(24)}$ documented that simultaneous multiple prescriptions of FA, ascorbic acid, and $\mathrm{N}$-acetyl cysteine are suggested to rescue the VPA-induced teratogenicity. Tunali et al. ${ }^{(25)}$ and Gezginci-Oktayoglu et al. ${ }^{(26)}$ showed that Vitamin E exerted antioxidant properties and may prevent lens ${ }^{(25)}$ and kidney ${ }^{(26)}$ damage caused by VPA.

Multiple studies tried to explore the mechanisms underlying the teratogenic risk of AED exposure and the prophylactic effects of vitamin E \&/or FA; Ornoy et al. ${ }^{(16)}$ reported that specific inhibition of histone deacetylase and changes in gene expression by VPA may explain its teratogenicity with other possible explanations as increased fetal oxidative stress induced by VPA, with the brain being more susceptible to oxidative stress in comparison to other fetal organs, or FA inhibitory action of VPA. Tung \& Winn ${ }^{(27)}$ experimentally found VPA exposure resulted in an increase in reactive oxygen species (ROS) staining in the head region and increased ROS levels were correlated with increased staining for apoptotic markers, and attributed developmental defects in head and neck region to these increased ROS levels.

Mallela \& Hrubec ${ }^{(28)}$ reported increased apoptosis as an underlying pathogenic mechanism involved in VPA teratogenicity, suggested that VPA may alter other cellular processes such as cell proliferation and differentiation in addition to apoptosis and concluded that VPA alters several biological processes in the developing embryos to induce fetal malformations. Umur et al. ${ }^{(29)}$ suggested that VPA may induce apoptotic mechanisms but not through the p53 pathway and FA effectively prevents the teratogenic influence of VPA on chick embryo at neurulation stages by stopping cascade of apoptosis before caspase 3 expression.

Tiboni et al. ${ }^{(30)}$ reported that after VPA $(400 \mathrm{mg} / \mathrm{kg})$ treatment $35.2 \%$ of fetuses exhibited skeletal teratogenesis, but this rate was significantly increased to $53.7 \%$ after nitric oxide synthase inhibitor N(G)-nitro-L-arginine methyl esther co-administration. Thereafter, in 2015; Tiboni \& Ponzano ${ }^{(31)}$ detected axial skeletal defects in $75.8 \%$ of VPA-exposed fetuses, but pre-treatment with sildenafil citrate which prolongs nitric oxide signaling significantly decreased the rate of skeletally affected fetuses to $61.6 \%$.

Recently, in 2015; Rubinchik-Stern et al. ${ }^{(32)}$, incubated human trophoblastic cells with multiple AED and found that 
compared with controls, AED-treated cells displayed half the levels of folate placental uptake carriers mRNA and protein and up to 2.7-fold increases in efflux transporters mRNA and protein expression, together with enhanced efflux transporters' activity and altered to a modest extent the transcription of nuclear receptors known to regulate transporter expression.

The obtained experimental results supported the clinical recommendations to judicious use of AED during pregnancy; the most recent are provided by the Task Force of the Commission on European Affairs of the International League Against Epilepsy and the European Academy of Neurology ${ }^{(33)}$ that where possible, VPA should be avoided in women of childbearing potential, VPA should not be prescribed as a first-line treatment for focal epilepsy unless pregnancy is highly unlikely or it is the most effective treatment and the risks and benefits of VPA and other treatment alternatives should be discussed with the patients.

Moreover, Tanoshima et al. ${ }^{(20)}$ performed meta-analyses of cohort studies to determine the time profiles of signal emergence and risk estimates of VPA-associated congenital malformations and identified 59 studies documented that risks of VPA-associated congenital malformations are 2-7 fold higher than other common antiepileptic drugs so it should not be used as a first-line therapy in women of childbearing age unless it is the only option for the patient.

It could be concluded that VPA chronic administration during pregnancy showed deleterious effects on fetal body measurements and skeletal system development. However, concomitant administration of vitamin $\mathrm{E}$ and FA showed significant ameliorative effect on these changes so, if it is strongly indicated, VPA can be used during pregnancy in combination with both vitamin $\mathrm{E}$ and FA.

\section{References}

[1] Chiba S: Comprehensive management for women with epilepsy. Brain Nerve. 2011; 63(4):301-8.

[2] Velíšková J, Desantis KA: Sex and hormonal influences on seizures and epilepsy. Horm Behav. 2013; 63(2):267-77.

[3] Nanau RM, Neuman MG: Adverse drug reactions induced by valproic acid. Clin Biochem. 2013; 46(15):1323-38.

[4] Fricke-Galindo I, Jung-Cook H, LLerena A, López-López M: Pharmacogenetics of adverse reactions to antiepileptic drugs. Neurologia. 2015. pii: S0213-4853(15)00056-0.

[5] Star K, Edwards IR, Choonara I: Valproic acid and fatalities in children: a review of individual case safety reports in VigiBase. PLoS One. 2014; 9(10):e108970.

[6] Vella T, Mifsud J: Interactions between valproic acid and quetiapine/olanzapine in the treatment of bipolar disorder and the role of therapeutic drug monitoring. J Pharm Pharmacol. 2014; 66(6):747-59.

[7] Perucca E: Optimizing antiepileptic drug treatment in tumoral epilepsy. Epilepsia. 2013; 54 Suppl 9:97-104.

[8] Kjaer I, Kjaer TW, Graem N: Ossification sequence of occipital bone and vertebrae in human fetuses. J Craniofac Genet Dev Biol. 1993; 13(2):83-8.
[9] Sliwonik I: Development of parietal bone based on ossification in the fetus. Ann Acad Med Stetin. 2002; 48:145-62.

[10] Cardoso HF, Ríos L: Age estimation from stages of epiphyseal union in the presacral vertebrae. Am J Phys Anthropol. 2011; 144(2):238-47.

[11] Olsen ØE, Lie RT, Lachman RS, Maartmann-Moe H, Rosendahl K: Ossification sequence in infants who die during the perinatal period: population-based references. Radiology. 2002; 225(1):240-4.

[12] Zhang Q, Wang H, Udagawa J, Otani H: Morphological and morphometric study on sphenoid and basioccipital ossification in normal human fetuses. Congenit Anom (Kyoto). 2011; 51(3):138-48.

[13] Garzón-Alvarado DA, González A, Gutiérrez ML: Growth of the flat bones of the membranous neurocranium: a computational model. Comput Methods Programs Biomed. 2013; 112(3):655-64.

[14] Burdan F, Szumiło J, Dudka J, Klepacz R, Błaszczak M, Solecki M, Korobowicz A, Chałas A, Klepacki J, Palczak M, Zuchnik-Wrona A, Hadała-Kiś A, Urbanowicz Z, Wójtowicz Z: Morphological studies in modern teratological investigations. Folia Morphol (Warsz). 2005; 64(1):1-8.

[15] Baran O, Nergiz Y, Tuncer MC: The effects of valproic acid, vitamin $\mathrm{E}$ and folic acid on ribs of rat fetuses in the prenatal period. Ann Anat. 2006;188(2):117-25.

[16] Ornoy A: Valproic acid in pregnancy: how much are we endangering the embryo and fetus? Reprod Toxicol. 2009; 28(1):1-10.

[17] Soysal H, Unur E, Düzler A, Karaca O, Ekinci N: Effects of intraperitoneal administration of the phenytoin on the skeletal system of rat fetus. Seizure. 2011; 20(3):187-93.

[18] Fadel RA, Sequeira RP, Abu-Hijleh MF, Obeidat M, Salem AH: Effect of prenatal administration of therapeutic doses of topiramate on ossification of ribs and vertebrae in rat fetuses. Rom J Morphol Embryol. 2012; 53(2):321-7.

[19] Koo J, Zavras A: Antiepileptic drugs (AEDs) during pregnancy and risk of congenital jaw and oral malformation. Oral Dis. 2013; 19(7):712-20.

[20] Tanoshima M, Kobayashi T, Tanoshima R, Beyene J, Koren G, Ito S: Risks of congenital malformations in offspring exposed to valproic acid in utero: A systematic review and cumulative meta-analysis. Clin Pharmacol Ther. 2015; Epub ahead of print.

[21] Al Deeb S, Al Moutaery K, Arshaduddin M, Tariq M: Vitamin $\mathrm{E}$ decreases valproic acid induced neural tube defects in mice. Neurosci Lett. 2000; 292(3):179-82.

[22] Padmanabhan R, Shafiullah MM: Amelioration of sodium valproate-induced neural tube defects in mouse fetuses by maternal folic acid supplementation during gestation. Congenit Anom (Kyoto). 2003; 43(1):29-40.

[23] Dawson JE, Raymond AM, Winn LM: Folic acid and pantothenic acid protection against valproic acid-induced neural tube defects in CD-1 mice. Toxicol Appl Pharmacol. 2006; 11(2):124-32.

[24] Hsieh CL, Wang HE, Tsai WJ, Peng CC, Peng RY: Multiple point action mechanism of valproic acid-teratogenicity alleviated by folic acid, vitamin $\mathrm{C}$, and $\mathrm{N}$-acetylcysteine in chicken embryo model. Toxicology. 2012;291(1-3):32-42. 
[25] Tunali S, Kahraman S, Yanardag R. Vitamin U, a novel free radical scavenger, prevents lens injury in rats administered with valproic acid. Hum Exp Toxicol. 2014. pii: 0960327114561665.

[26] Gezginci-Oktayoglu S, Turkyilmaz IB, Ercin M, Yanardag R, Bolkent S. Vitamin U has a protective effect on valproic acid-induced renal damage due to its anti-oxidant, anti-inflammatory, and anti-fibrotic properties. Protoplasma. 2015. [Epub ahead of print]

[27] Tung EW, Winn LM: Valproic acid increases formation of reactive oxygen species and induces apoptosis in postimplantation embryos: a role for oxidative stress in valproic acid-induced neural tube defects. Mol Pharmacol. 2011; 80(6):979-87.

[28] Mallela M, Hrubec T: Reduction in valproic acid-induced neural tube defects by maternal immune stimulation: role of apoptosis. Birth Defects Res B Dev Reprod Toxicol. 2012; 95(4):296-303.
[29] Umur AS, Selcuki M, Bursali A, Umur N, Kara B, Vatansever HS, Duransoy YK: Simultaneous folate intake may prevent adverse effect of valproic acid on neurulating nervous system. Childs Nerv Syst. 2012; 28(5):729-37.

[30] Tiboni GM, Chiarelli F, Verrotti A: Inhibition of nitric oxide synthesis enhances teratogenic effects induced by valproic Acid. In Vivo. 2013; 27(4):513-8.

[31] Tiboni GM, Ponzano A: Prevention of valproic acid-induced neural tube defects by sildenafil citrate. Reprod Toxicol. 2015; pii: S0890-6238(15)00038-6.

[32] Rubinchik-Stern M, Shmuel M, Eyal S: Antiepileptic drugs alter the expression of placental carriers: An in vitro study in a human placental cell line. Epilepsia. 2015; 56(7):1023-32.

[33] Tomson T, Marson A, Boon P, Canevini MP, Covanis A, Gaily E, Kälviäinen R, Trinka E: Valproate in the treatment of epilepsy in girls and women of childbearing potential. Epilepsia. 2015;56(7):1006-19. 